\title{
Confined Plunging Liquid Jets for Dilution of Brine from Desalination Plants
}

\author{
Ishita Shrivastava ${ }^{1, *}+\mathbb{D}^{\mathbb{D}}$, Edward Eric Adams ${ }^{2} \mathbb{D}$, Bader Al-Anzi $^{3} \mathbb{D}$, Aaron Chunghin Chow 4 \\ and Jongyoon Han ${ }^{1} \mathbb{D}$
}

1 Department of Electrical Engineering and Computer Science, Massachusetts Institute of Technology, Cambridge, MA 02139, USA; jyhan@mit.edu

2 Department of Civil and Environmental Engineering, Massachusetts Institute of Technology, Cambridge, MA 02139, USA; eeadams@mit.edu

3 Department of Environmental Technologies and Management, Kuwait University, POB 5969, Safat 13060, Kuwait; bader.alanzi@ku.edu.kw

4 Division of Engineering, New York University, Abu Dhabi 129188, United Arab Emirates; cc6307@nyu.edu

* Correspondence: ishita@mit.edu

† Currently at: Gradient, One Beacon Street, Boston, MA 02108, USA.

Citation: Shrivastava, I.; Adams, E.E.; Al-Anzi, B.; Chow, A.C.; Han, J. Confined Plunging Liquid Jets for Dilution of Brine from Desalination Plants. Processes 2021, 9, 856. https:// doi.org/10.3390/pr9050856

Academic Editors: Farzaneh Mahmoudi and Aliakbar Akbarzadeh

Received: 11 April 2021

Accepted: 8 May 2021

Published: 13 May 2021

Publisher's Note: MDPI stays neutral with regard to jurisdictional claims in published maps and institutional affiliations.

Copyright: (c) 2021 by the authors. Licensee MDPI, Basel, Switzerland. This article is an open access article distributed under the terms and conditions of the Creative Commons Attribution (CC BY) license (https:// creativecommons.org/licenses/by/ $4.0 /)$.

\begin{abstract}
Confined plunging jets are investigated as potential outfalls for the discharge of desalination brine. Compared to offshore submerged outfalls that rely on momentum to induce mixing, plunging jets released above the water surface utilize both momentum and negative buoyancy. Plunging jets also introduce air into the water column, which can reduce the possibility of hypoxic zones. In contrast to unconfined plunging jets, confined plunging jets include a confining tube, or downcomer, around the jet, which increases the penetration depth of the bubbles and can provide better aeration. However, the presence of this downcomer can hinder mixing with surrounding water. Therefore, laboratory measurements of dilution are reported here and compared to the dilution of unconfined plunging jets. In addition, qualitative observations of bubble penetration depth are also used to discuss aeration potential. For designs that increase the bubble penetration depth as compared to unconfined plunging jets, results show that dilution decreases as the depth of the downcomer is increased. However, it is shown that confined plunging jets can be designed with a short downcomer to provide higher dilution than unconfined jets. The effect of the diameter of downcomer on dilution is also investigated and a non-monotonic effect is observed.
\end{abstract}

Keywords: plunging jet; desalination; brine; dilution; aeration; air entrainment; multiphase flow; outfall

\section{Introduction}

Seawater desalination is a major source of freshwater for many parts of the world. In particular, countries bordering the Arabian Gulf are heavily reliant on seawater desalination for their freshwater supply, and contribute to 33\% of the global desalination capacity [1]. A by-product of seawater desalination is reject brine, which is typically discharged back to the sea. Reject brine can have up to twice the salinity of seawater and, unless highly diluted, can significantly impact the marine environment. Depending on the process, brine may also contain other contaminants such as anti-fouling and anti-scaling agents, which can be harmful to benthic organisms as well [2-5].

At some locations, especially those with shallow water, brine is pre-mixed with seawater or power plant cooling water and discharged using surface canals (Figure 1a), which provide limited mixing with ambient water [2]. However, to get better mixing, brine can be discharged using high momentum submerged outfalls [6-9] or buoyancy dominated surface outfalls (shown in Figure 1b,c, respectively). These outfalls result in rapid mixing of brine with ambient water in the near-field (within a few hundred meters from the discharge 
location), and the reduction in contaminant concentrations due to the mixing generated by these outfalls is comparable [10].

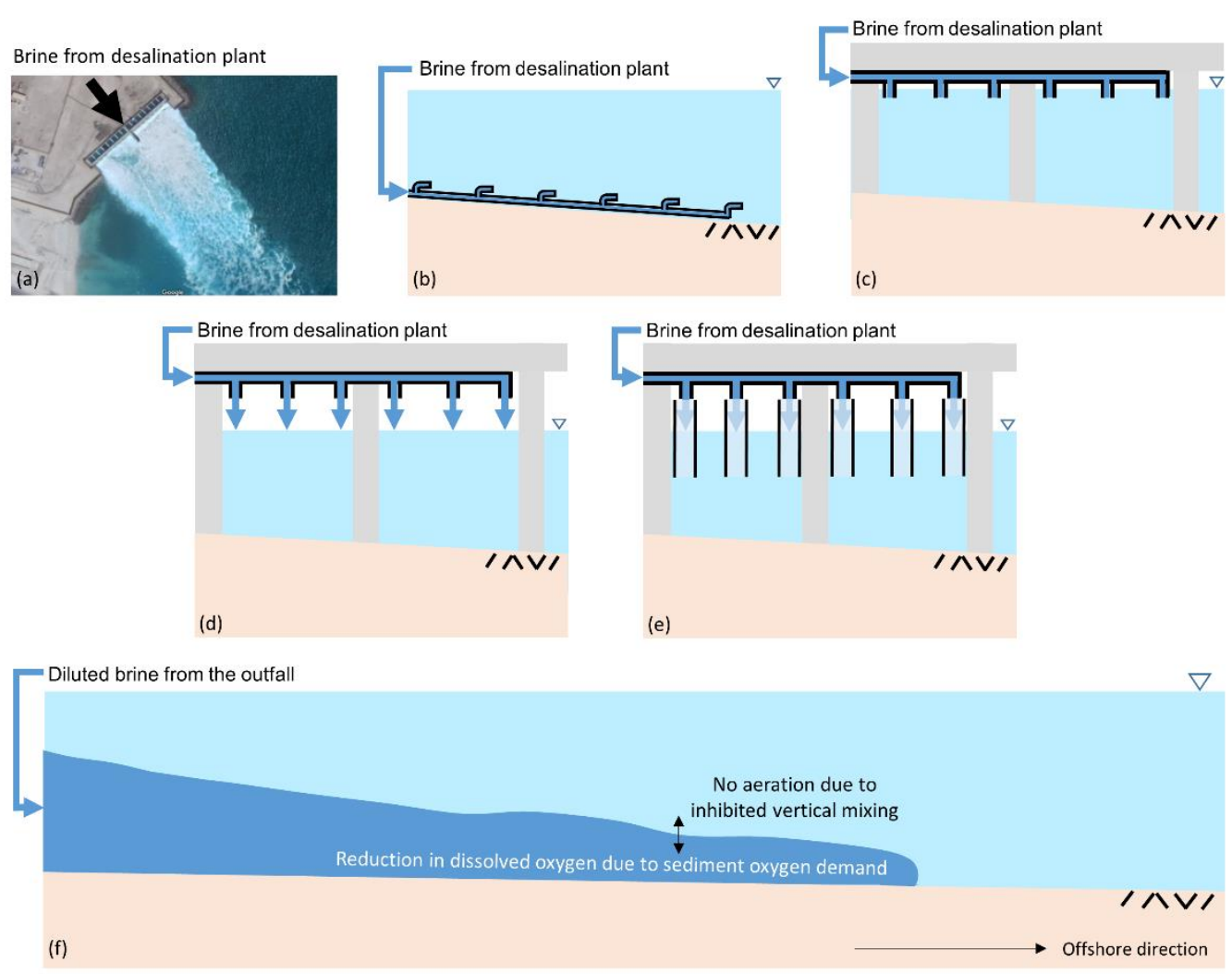

Figure 1. Different types of outfalls for the discharge of brine: (a) Surface discharge, (b) momentum dominated submerged multiport discharge, (c) buoyancy dominated surface multiport discharge, (d) unconfined plunging jets, and (e) confined plunging jets. Diluted brine from any of these outfalls can spread along the seafloor and result in a thin layer with low dissolved oxygen (f). (Figure modified from [10].)

Negatively buoyant diluted brine tends to spread on the seafloor leading to density stratification, which inhibits vertical mixing between the bottom layer of diluted brine and the relatively fresh surface layer (Figure 1f). As a result, the dissolved oxygen in the bottom layer is not replenished and hypoxic or anoxic conditions can develop due to the sediment oxygen demand acting on the bottom layer [5,11-13]. Hypoxic conditions can strongly affect benthic organisms and have been associated with decline in fish production, fish kills and significant trophic implications [14-16].

In addition to the induced vertical stratification, high salinity and temperature of ambient seawater can exacerbate the problem as oxygen saturation decreases with an increase in temperature and salinity, e.g., oxygen saturation decreases from $9.1 \mathrm{mg} / \mathrm{L}$ for freshwater at $20^{\circ} \mathrm{C}$ to $6.2 \mathrm{mg} / \mathrm{L}$ for seawater with salinity of $35 \mathrm{psu}$ at $30{ }^{\circ} \mathrm{C}$ [17]. Development of hypoxia in bottom waters has previously been correlated with vertical stratification and warm water temperatures in estuaries [16,18-20], but the dense layer at the bottom can also form at other locations, e.g., offshore from a desalination plant outfall.

In order to avoid possible hypoxia as a consequence of brine discharge from desalination plants, discharge methods that actively increase aeration in the water column, in addition to providing mixing with the receiving water, should be explored. The plunging liquid jet reactor (PLJR) is one such outfall design. Plunging liquid jet reactors (Figure 1d) involve vertically downward discharge of a liquid phase (brine) from a jet that is located above the surface of the receiving water. As the jet falls through the headspace, it entrains air, which is then injected into the receiving water with the plunging jet. The downward 
momentum and negative buoyancy of the jet provide mixing with the receiving water and the entrained air promotes reaeration.

Plunging jet reactors have been used in the past with neutrally buoyant effluent to achieve high mass transfer from the gas phase to the liquid phase at low operating costs [21]. This is done by entraining gas bubbles into the liquid and increasing the contact time between the two phases. Plunging jet reactors are used in different processes such as gas-liquid reactors in the chemical industry, aerobic wastewater treatment, air pollution abatement, froth flotation and fermentation [22]. The oxygen transfer efficiency of plunging jets is comparable to other aeration technologies $[10,23,24]$.

Many studies have focused on understanding the mechanisms of air entrainment and measuring the air entrainment and mass transfer associated with plunging jets discharging neutrally buoyant effluent [22,24-28]. However, not many have investigated the mixing capacity of plunging jets, especially for the discharge of dense effluents such as brine. Recently, mixing of plunging jets was studied by Chow et al. [10]. Dilution measured near the bottom showed a non-monotonic effect of the plunging jet height above the receiving water surface: for small heights, dilution decreased with height due to the loss of momentum caused by the splash, while for larger heights dilution increased with height due to the greater momentum due to gravity.

A variant of the plunging liquid jet reactor is the confined plunging jet reactor which includes a vertical confining tube, or downcomer, concentric with the jet and partially immersed in the receiving water (Figure 1e). Confined plunging jets have been theorized to provide better mass transfer in comparison to unconfined plunging jets by confining the bubbly jet region and increasing the penetration depth of the bubbles, which, in turn, leads to an increased contact time between the gas and the liquid phase [24,29-31] However, they have not been widely investigated and experimental measurements of the air entrainment and mass transfer rate have not clearly indicated better performance in comparison to unconfined jets [24,26,29]. Two different types of air entrainment rates have been measured in these studies - the net air entrainment (amount of air that exits at the bottom of the downcomer) and the gross air entrainment (total amount of air entrained by the jet including any air that is then dis-entrained and rises to the surface within the downcomer).

Ohkawa et al. [26] made measurements of air entrainment rate for both unconfined and confined plunging jets, and found the net air entrainment rate of confined jets to be higher (by 25-60\%) than unconfined jets at comparable operating conditions. For confined jets with long and narrow downcomers, they saw an increase in net air entrainment rate with increasing downcomer diameter, and decrease with increasing downcomer depth.

Low [24] made measurements of gross air entrainment rate for confined plunging jets and compared it to measurements of air entrainment for unconfined plunging jets. A significant effect of downcomer diameter on gross air entrainment rate was not observed. The empirical equations proposed by Low [24] suggested that the air entrainment rate for a confined jet is $60-75 \%$ of that for an unconfined jet.

Al-Anzi et al. [30] made measurements of net air entrainment rate for different downcomer diameters and submergence depth. They observed maximum air entrainment rate when the ratio of downcomer diameter to nozzle diameter was close to 5 . They did not find a strong dependence on downcomer depth.

To the authors' knowledge, plunging jet systems (either unconfined or confined) have not been considered as potential outfalls for brine discharge from desalination plants except in our recent work by Chow et al. [10], which looked at unconfined plunging jets. This paper aims to evaluate the mixing performance of confined plunging jets when used to discharge a negatively buoyant effluent like brine. Measurements of dilution for confined plunging jets are presented in this paper, focusing on the effects of density difference between the effluent and receiving water, and the diameter and depth of submergence of the downcomer. Dilution measurements for confined plunging jets are also compared 
to dilution of unconfined plunging jets under similar operating conditions. Qualitative observations of the jet behavior and bubble penetration depth are also presented.

\section{Formulation}

The situation analyzed in this paper is that of a confined plunging jet reactor which consists of a nozzle with diameter $\mathrm{d}_{0}\left(\right.$ area $\left.\mathrm{a}_{0}=(\pi / 4) \mathrm{d}_{0}{ }^{2}\right)$ discharging high salinity effluent (brine) vertically downward in quiescent receiving water with depth $\mathrm{H}$. The flow rate of brine is $\mathrm{Q}_{\mathrm{b}}$, its density is $\rho_{\mathrm{b}}$ (salinity difference with respect to receiving water is $\Delta \mathrm{s}$ ), and the velocity of brine exiting the nozzle is $\mathrm{v}_{0}=\mathrm{Q}_{\mathrm{b}} / \mathrm{a}_{0}$. The height of the jet above the water surface in the receiving pool (or the "jet length") is $\mathrm{L}_{\mathrm{j}}$. A vertical confining tube (or downcomer) of diameter $\mathrm{D}_{\mathrm{c}}$ (cross-sectional area $\mathrm{A}_{\mathrm{c}}=(\pi / 4) \mathrm{D}_{\mathrm{c}}{ }^{2}$ ) is placed concentrically with the jet. The downcomer is partially submerged in the receiving water and its depth of submergence is $\mathrm{H}_{\mathrm{c}}$. The radial distance outward from the nozzle axis is $\mathrm{R}$ (Figure 2). The rise in the water level within the downcomer is denoted by $\mathrm{H}_{R}$. The flow rate of net air entrained by the jet is denoted as $Q_{a}$. Gross air entrainment rate is denoted as $Q_{g}$. The bubble penetration depths (the maximum depth to which bubbles propagate below the receiving water surface) for unconfined and confined jets are denoted as $\mathrm{H}_{\mathrm{pu}}$ and $\mathrm{H}_{\mathrm{pc}}$, respectively.

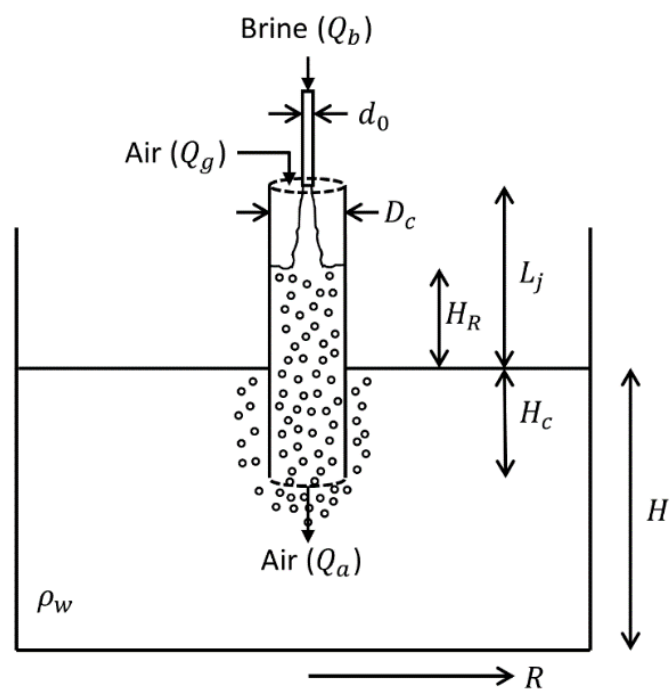

Figure 2. Definition sketch for a confined plunging jet reactor.

\section{Materials and Methods}

Experiments to measure dilution of confined plunging jets were conducted in a tank with dimensions of $480 \mathrm{~cm}$ (length) $\times 120 \mathrm{~cm}$ (width) $\times 60 \mathrm{~cm}$ (depth). The tank was filled with fresh water with a depth of $50 \mathrm{~cm}$ for most runs and acted as the receiving water pool. Salt water (brine) was stored in a separate reservoir with a capacity of $140 \mathrm{~L}$. A submersible pump was used to supply this salt water to a stainless steel nozzle, with a length of $30 \mathrm{~cm}$ and diameter of $1 \mathrm{~cm}$, which discharged it vertically downward into the receiving pool. The distance between the nozzle and the surface of water in the receiving pool was equal to the jet length. Clear acrylic pipes of different diameters were used as the downcomer and were suspended concentric to the nozzle.

The experiments modeled one plunging jet out of an array of multiple jets discharging brine from a desalination plant. For example, consider a total brine flow rate of $1 \mathrm{~m}^{3} / \mathrm{s}$ with 6 jets (flow rate per jet $=0.167 \mathrm{~m}^{3} / \mathrm{s}$ ). Using Froude scaling, and the experimental brine flow rate of $160 \mathrm{~cm}^{3} / \mathrm{s}$, the volume ratio between the prototype and the model is $\mathrm{Q}_{\mathrm{r}}=\left(0.167 \mathrm{~m}^{3} / \mathrm{s}\right) /\left(160 \mathrm{~cm}^{3} / \mathrm{s}\right)=1042$, resulting in a length ratio of $\mathrm{L}_{\mathrm{r}}=\mathrm{Q}_{\mathrm{r}}{ }^{0.4} \approx 16$. Thus, the receiving water depth of $50 \mathrm{~cm}$ and the nozzle diameter of $1 \mathrm{~cm}$ in the experiments scale to a water depth of $8 \mathrm{~m}$ and nozzle diameter of $0.16 \mathrm{~m}$ in the field. The jet length 
was varied between 0 and $60 \mathrm{~cm}$ ( 0 to $9.6 \mathrm{~m}$ in the prototype) and the salinity difference between brine and receiving water was either 40 psu or $10 \mathrm{psu}$. These values of the salinity difference represent brine from a reverse osmosis plant without any pre-dilution, and brine pre-diluted with seawater or power plant cooling water, respectively [8]. The downcomer diameter was varied between $2.5 \mathrm{~cm}$ and $14.6 \mathrm{~cm}$ with the downcomer submergence depth varied between 5 and $45 \mathrm{~cm}$ below the receiving water surface. Table 1 lists the experimental parameters for all the experiments.

Table 1. Experimental parameters.

\begin{tabular}{|c|c|c|c|c|c|c|c|c|c|c|c|c|}
\hline Run & $\mathrm{L}_{\mathrm{j}}(\mathrm{cm})$ & $\begin{array}{c}D_{c} \\
(\mathrm{~cm})\end{array}$ & $\begin{array}{c}\Delta s \\
(\mathrm{psu})\end{array}$ & $\begin{array}{c}\mathrm{H}_{\mathrm{c}} \\
(\mathrm{cm})\end{array}$ & $\mathbf{H}(\mathrm{cm})$ & $\mathbf{N}$ & $\mathrm{c}_{\text {mean }} / \mathrm{c}_{0}$ & $\sigma_{\text {mean }} / c_{0}$ & CV (\%) & $\mathbf{S}$ & Range of S & $\mathrm{H}_{\mathrm{R}}(\mathrm{cm})$ \\
\hline 1 & 60 & 14.6 & 10 & 15 & 50 & 3 & 0.08 & 0.003 & 18 & 12 & $11.5-12.5$ & 1 \\
\hline 2 & 60 & 14.6 & 10 & 30 & 50 & 3 & 0.15 & 0.002 & 15 & 7 & $6.9-7.1$ & 1 \\
\hline 3 & 60 & 14.6 & 40 & 15 & 50 & 3 & 0.06 & 0.0005 & 14 & 15 & $14.9-15.1$ & 1 \\
\hline 4 & 60 & 14.6 & 40 & 30 & 50 & 3 & 0.11 & 0.001 & 15 & 9 & $8.96-9.04$ & 1 \\
\hline 5 & 60 & 8.9 & 10 & 15 & 50 & 4 & 0.09 & 0.004 & 13 & 11 & $10.6-11.4$ & 2.5 \\
\hline 6 & 60 & 8.9 & 10 & 30 & 50 & 3 & 0.20 & 0.010 & 14 & 5 & $4.8-5.3$ & 3 \\
\hline 7 & 60 & 8.9 & 40 & 15 & 50 & 4 & 0.07 & 0.002 & 10 & 14 & $13.7-14.3$ & 2 \\
\hline 8 & 60 & 8.9 & 40 & 30 & 50 & 3 & 0.12 & 0.001 & 13 & 8 & 7.9-8.1 & 2.5 \\
\hline 9 & 60 & 4.4 & 10 & 5 & 50 & 5 & 0.04 & 0.005 & 27 & 24 & $21.4-27.3$ & -1 \\
\hline 10 & 60 & 4.4 & 10 & 10 & 50 & 6 & 0.03 & 0.001 & 14 & 32 & $30.8-33.3$ & 0.5 \\
\hline 11 & 60 & 4.4 & 10 & 15 & 50 & 10 & 0.04 & 0.011 & 23 & 23 & $18.6-30.3$ & 5 \\
\hline 12 & 60 & 4.4 & 10 & 20 & 50 & 4 & 0.13 & 0.003 & 8 & 8 & $7.8-8.2$ & 9.5 \\
\hline 13 & 60 & 4.4 & 10 & 25 & 50 & 4 & 0.17 & 0.004 & 10 & 6 & $5.9-6.1$ & 13 \\
\hline 14 & 60 & 4.4 & 10 & 30 & 50 & 5 & 0.21 & 0.022 & 19 & 5 & $4.5-5.6$ & 18 \\
\hline 15 & 60 & 4.4 & 10 & 40 & 50 & 3 & 0.26 & 0.024 & 36 & 4 & $3.7-4.4$ & 25.5 \\
\hline 16 & 60 & 4.4 & 10 & 45 & 50 & 3 & 0.42 & 0.024 & 30 & 2 & $1.9-2.1$ & 29.5 \\
\hline 17 & 60 & 4.4 & 40 & 15 & 50 & 5 & 0.05 & 0.007 & 15 & 18 & $16.0-20.5$ & 4 \\
\hline 18 & 60 & 4.4 & 40 & 30 & 50 & 6 & 0.12 & 0.022 & 27 & 8 & $6.8-9.7$ & 17 \\
\hline 19 & 60 & 2.5 & 10 & 15 & 50 & 4 & 0.04 & 0.011 & 22 & 24 & $18.8-33.0$ & -4 \\
\hline 20 & 60 & 2.5 & 10 & 30 & 50 & 5 & 0.12 & 0.027 & 44 & 9 & $7.4-11.6$ & 4.5 \\
\hline 21 & 60 & 2.5 & 40 & 15 & 50 & 4 & 0.04 & 0.002 & 19 & 23 & $22.0-24.0$ & -5 \\
\hline 22 & 60 & 2.5 & 40 & 30 & 50 & 4 & 0.10 & 0.006 & 25 & 10 & $9.4-10.7$ & 3 \\
\hline 23 & 60 & 4.4 & 10 & 20 & 40 & 3 & 0.19 & 0.011 & 12 & 5 & $4.7-5.3$ & 10 \\
\hline 24 & 60 & 4.4 & 10 & 15 & 35 & 4 & 0.08 & 0.009 & 35 & 13 & $11.6-14.8$ & 5 \\
\hline 25 & 60 & 4.4 & 10 & 10 & 30 & 2 & 0.04 & 0.001 & 20 & 23 & $22.4-23.6$ & -0.5 \\
\hline 26 & 30 & 4.4 & 10 & 10 & 50 & 3 & 0.06 & 0.005 & 19 & 18 & $16.6-19.7$ & -0.5 \\
\hline 27 & 30 & 4.4 & 10 & 15 & 50 & 4 & 0.10 & 0.011 & 14 & 10 & $9.1-11.2$ & 3 \\
\hline 28 & 30 & 4.4 & 10 & 30 & 50 & 4 & 0.20 & 0.020 & 24 & 5 & $4.5-5.5$ & 13.5 \\
\hline 29 & 30 & 4.4 & 40 & 15 & 50 & 3 & 0.08 & 0.005 & 17 & 13 & $12.2-13.9$ & 2.5 \\
\hline 30 & 30 & 4.4 & 40 & 30 & 50 & 4 & 0.13 & 0.019 & 22 & 8 & $7.0-9.3$ & 12 \\
\hline 31 & 15 & 4.4 & 10 & 10 & 50 & 2 & 0.07 & 0.001 & 20 & 14 & $13.8-14.2$ & \\
\hline 32 & 0 & 4.4 & 10 & 10 & 50 & 3 & 0.05 & 0.002 & 16 & 18 & $17.3-18.8$ & \\
\hline 33 & 60 & & 10 & & 50 & 9 & 0.04 & 0.004 & 25 & 24 & $22.1-26.3$ & \\
\hline 34 & 60 & & 40 & & 50 & 4 & 0.04 & 0.002 & 13 & 24 & $23.0-25.0$ & \\
\hline 35 & 30 & & 10 & & 50 & 4 & 0.09 & 0.011 & 24 & 11 & $9.8-12.5$ & \\
\hline 36 & 30 & & 40 & & 50 & 3 & 0.06 & 0.002 & 17 & 17 & $16.4-17.6$ & \\
\hline 37 & 15 & & 10 & & 50 & 3 & 0.10 & 0.013 & 15 & 10 & 8.9-11.4 & \\
\hline 38 & 0 & & 10 & & 50 & 3 & 0.06 & 0.006 & 14 & 17 & $15.4-18.9$ & \\
\hline
\end{tabular}

A fluorescent dye (Rhodamine 6G) was added to the salt water discharging from the nozzle (discharge concentration $=\mathrm{c}_{0}$ ) and a fluorometer (Turner Designs Cyclops 7) was used to measure its concentration along the tank bottom at a radial distance of $50 \mathrm{~cm}$ from the nozzle. The fluorometer was calibrated with known concentrations of the fluorescent dye prior to experiments, which resulted in a linear calibration curve. The fluorescence 
probe measured concentration at a height of about $1.2 \mathrm{~cm}$ above the tank bottom. The fluorometer took measurements every second and each experiment was run for a duration of $6 \mathrm{~min}$. Only the measurements taken after $3 \mathrm{~min}$ from the start (when the discharge of brine began) were used as the measurements appeared to be quasi-steady after 3 min for all experiments. Each experiment was also repeated (with the number of replicates $=\mathrm{N}$ ).

The mean concentration $\left(c_{\text {mean }}\right)$ and the standard deviation of the mean $\left(\sigma_{\text {mean }}\right)$ from these repeated runs are reported in Table 1 relative to the discharge concentration. The coefficient of variation (CV) from individual runs averaged over the repeated runs for an experiment is also reported in Table 1. For example, for run 1, the measured relative concentrations (mean \pm standard deviation) are $0.080 \pm 0.015,0.084 \pm 0.015$ and $0.076 \pm 0.013$ from the 3 replicates. In this case, $c_{\text {mean }} / c_{0}$ is the average of the 3 mean values (equal to $0.080), \sigma_{\text {mean }} / c_{0}$ is the standard deviation of the 3 mean values (equal to 0.003 ), and $C V$ is the average of $0.015 / 0.080,0.015 / 0.084$ and $0.013 / 0.076$, equivalent to $18 \%$.

The measured concentrations are used to calculate mean dilution $(S) n$ the tank bottom at $\mathrm{R}=50 \mathrm{~cm}\left(\mathrm{~S}=\mathrm{c}_{0} / \mathrm{c}_{\text {mean }}\right)$. The range of mean dilution is from $\mathrm{c}_{0} /\left(\mathrm{c}_{\text {mean }}+\sigma_{\text {mean }}\right)$ to $\mathrm{c}_{0} /\left(\mathrm{c}_{\text {mean }}-\sigma_{\text {mean }}\right)$ and is also listed in Table 1 . This range is also shown in subsequent figures as "error bars." This mean dilution reflects the average factor by which excess salinity and concentrations of other contaminants of concern present in brine are reduced.

The height of rise of water level inside the downcomer and the maximum penetration depth of bubbles were also observed visually. The height of rise of water level inside the downcomer is reported in Table 1, whereas the observations of bubble penetration depth are used qualitatively to discuss the aeration potential of confined plunging jets. In addition to experiments with confined plunging jets, some experiments were also conducted to measure dilution for unconfined jets (runs 33-38) to compare with the corresponding experiments with confined jets.

\section{Results}

\subsection{Confined Plunging Jet Behavior}

Confined plunging jets behave similarly to unconfined plunging jets which are described in detail by Chow et al. [10]. The jet entrains air as it falls through the headspace and this entrained air is injected in the water column with the jet. However, depending on the diameter and submergence depth of the downcomer, the bubbles can be transported outside the downcomer or rise within the downcomer.

For an unconfined jet with $L_{j}=60 \mathrm{~cm}$ and $\Delta s=10 \mathrm{psu}$ (run 33), the bubble penetration depth was measured to be $20 \mathrm{~cm}$. However, bubbles can be pushed deeper with a narrow downcomer with large $\mathrm{H}_{\mathrm{c}}$. For example, with the $4.4 \mathrm{~cm}$ wide downcomer, bubbles were seen escaping from the bottom of the downcomer and rising outside it even with $\mathrm{H}_{\mathrm{C}}=45 \mathrm{~cm}$. Similarly, bubbles exited from the bottom of the downcomer for $\mathrm{H}_{\mathrm{c}}=30 \mathrm{~cm}$ with $\mathrm{D}_{\mathrm{c}}=2.5 \mathrm{~cm}$. For the case with $\mathrm{D}_{\mathrm{c}}=4.4 \mathrm{~cm}$ and $\mathrm{H}_{\mathrm{c}}=45 \mathrm{~cm}$, the rise in water level inside the downcomer $\left(\mathrm{H}_{\mathrm{R}}\right)$ was $29.5 \mathrm{~cm}$. So, for the bubbles to be able to exit the downcomer with $\mathrm{H}_{\mathrm{C}}$ as large as $45 \mathrm{~cm}$, the downcomer needs to extend to at least $30 \mathrm{~cm}$ above the surface of receiving water. Otherwise, enough head cannot be generated to push the bubbles out of the downcomer.

For $\mathrm{H}_{\mathrm{c}}=15 \mathrm{~cm}$, the bubbles penetrated deeper than the downcomer for all four downcomer diameters, but most of the bubbles were seen rising within the downcomer for $D_{c}=8.9$ and $14.6 \mathrm{~cm}$. Therefore, the net air entrainment for these runs is close to zero; however, aeration is expected to take place within the downcomer. For a downcomer submergence depth of $30 \mathrm{~cm}$, bubbles did not reach the lower end of the downcomer for $\mathrm{D}_{\mathrm{c}}=8.9$ and $14.6 \mathrm{~cm}$ and rose within the downcomer with a penetration depth of about $20 \mathrm{~cm}$ (same as that for an unconfined jet under similar conditions). Thus, runs with wide downcomers did not result in increased bubble penetration depths even with $\mathrm{H}_{\mathrm{c}}>\mathrm{H}_{\mathrm{pu}}$. For the two narrow downcomers, the flow within the downcomer appeared to be one-dimensional with most of the bubbles exiting the downcomer and rising outside it. 
Figure 3 shows a side view of bubbles inside the downcomer for various combinations of $\mathrm{D}_{\mathrm{c}}$ and $\mathrm{H}_{\mathrm{c}}$ for experiments with $\Delta \mathrm{s}=10 \mathrm{psu}$. Experiments with $\Delta \mathrm{s}=40 \mathrm{psu}$ looked similar to $\Delta \mathrm{s}=10 \mathrm{psu}$, except that many very fine bubbles were also observed for experiments with $\Delta \mathrm{s}=40 \mathrm{psu}$. These bubbles reached the bottom of the tank and spread radially for some distance with the diluted brine.

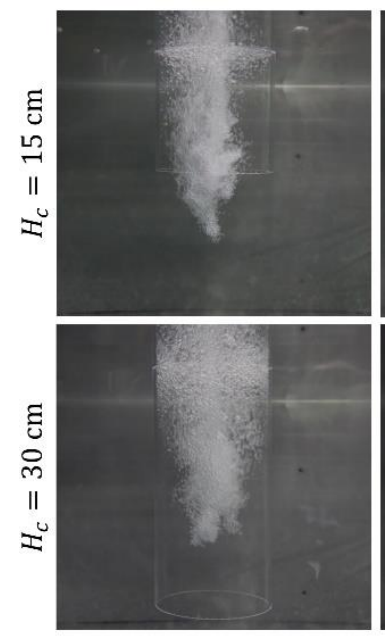

$D_{c}=14.6 \mathrm{~cm}$
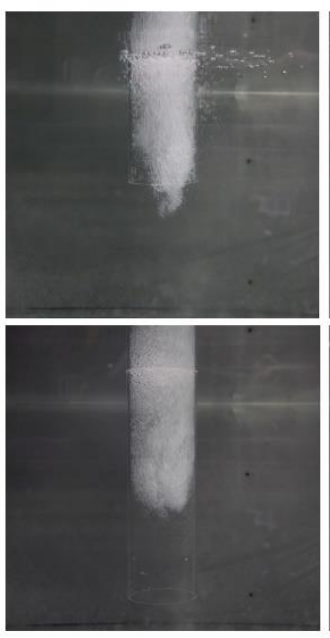

$D_{c}=8.9 \mathrm{~cm}$

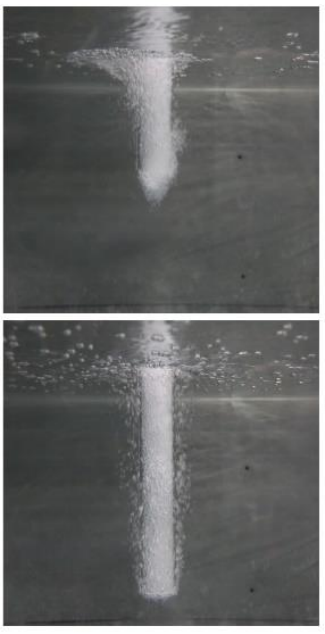

$D_{c}=4.4 \mathrm{~cm}$

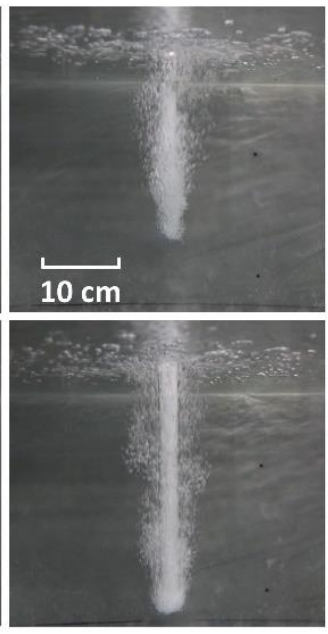

$D_{c}=2.5 \mathrm{~cm}$

Figure 3. Side view of the bubble plume within the downcomer for experiments with $L_{j}=60 \mathrm{~cm}$ and $\Delta \mathrm{s}=10 \mathrm{psu}$.

\subsection{Dilution}

To determine their effect on dilution, each variable of importance was varied independently while other variables were held constant. The effects of different variables are discussed below.

\subsubsection{Effect of Downcomer Submergence Depth}

Two sets of experiments were conducted with $\mathrm{L}_{\mathrm{j}}=60 \mathrm{~cm}, \mathrm{D}_{\mathrm{c}}=4.4 \mathrm{~cm}$ and $\Delta \mathrm{s}=10 \mathrm{psu}$ to investigate the effect of downcomer submergence depth on the dilution of confined jets. For the first set (runs 9-16), the depth of receiving water was held constant at $50 \mathrm{~cm}$ and $\mathrm{H}_{\mathrm{C}}$ was varied from $5 \mathrm{~cm}$ to $45 \mathrm{~cm}$. For the second set (runs 14 and 23-25), the water depth was also varied along with $\mathrm{H}_{\mathrm{c}}$ such that the distance between the bottom of the downcomer and the bottom of the tank $\left(\mathrm{H}-\mathrm{H}_{\mathrm{c}}\right)$ was held constant at $20 \mathrm{~cm}$.

Figures 4 and 5 show measured dilutions plotted as a function of $\mathrm{H}_{\mathrm{c}}$ for the first and second sets of experiments, respectively. The dilution of an unconfined jet with $\mathrm{L}_{\mathrm{j}}=60 \mathrm{~cm}$ and $\Delta s=10 \mathrm{psu}$ (run 33) is also plotted in Figure 4 at $\mathrm{H}_{\mathrm{c}} \approx 0$. The effect of $\mathrm{H}_{\mathrm{c}}$ on dilution is non-monotonic for experiments with constant $\mathrm{H}$, but dilution generally decreases with an increase in $\mathrm{H}_{\mathrm{c}}$. For experiments with fixed $\mathrm{H}-\mathrm{H}_{\mathrm{c}}$, dilution decreases with an increase in $\mathrm{H}_{\mathrm{c}}$ for small $\mathrm{H}_{\mathrm{c}}$, but becomes constant for large $\mathrm{H}_{\mathrm{c}}$.

For confined plunging jets, mixing with ambient water can occur both within the downcomer and outside the downcomer. The length of the eddy circulation region surrounding the jet is about $3-5 D_{c}$ from the nozzle [31,32]. If the downcomer submergence is larger than this length, the jet is not able to entrain fresh water from outside (below) the downcomer and the entrainment demand is supplied by recirculated brine. Therefore, for long downcomers $\left(\mathrm{H}_{\mathrm{c}}>3-5 \mathrm{D}_{\mathrm{c}}\right.$ or $\mathrm{H}_{\mathrm{c}}>18 \mathrm{~cm}$ for $\left.\mathrm{D}_{\mathrm{c}}=4.4 \mathrm{~cm}\right)$, most of the mixing with ambient water takes place after brine exits the downcomer and dilution depends on the depth of receiving water below the downcomer $\left(\mathrm{H}-\mathrm{H}_{\mathrm{c}}\right)$. Thus, dilution decreases with an increase in $\mathrm{H}_{\mathrm{C}}$ for experiments with constant $\mathrm{H}$ (Figure 4), while the two runs with $\mathrm{H}_{\mathrm{c}}=20$ and $30 \mathrm{~cm}$ have the same dilution when $\mathrm{H}-\mathrm{H}_{\mathrm{c}}$ is held constant (Figure 5). However, as seen in Figure 5, confined jets with short downcomers can get higher dilution with the 
same $\mathrm{H}-\mathrm{H}_{\mathrm{c}}$ because fresh water from outside can enter the downcomer allowing dilution to occur within the downcomer.

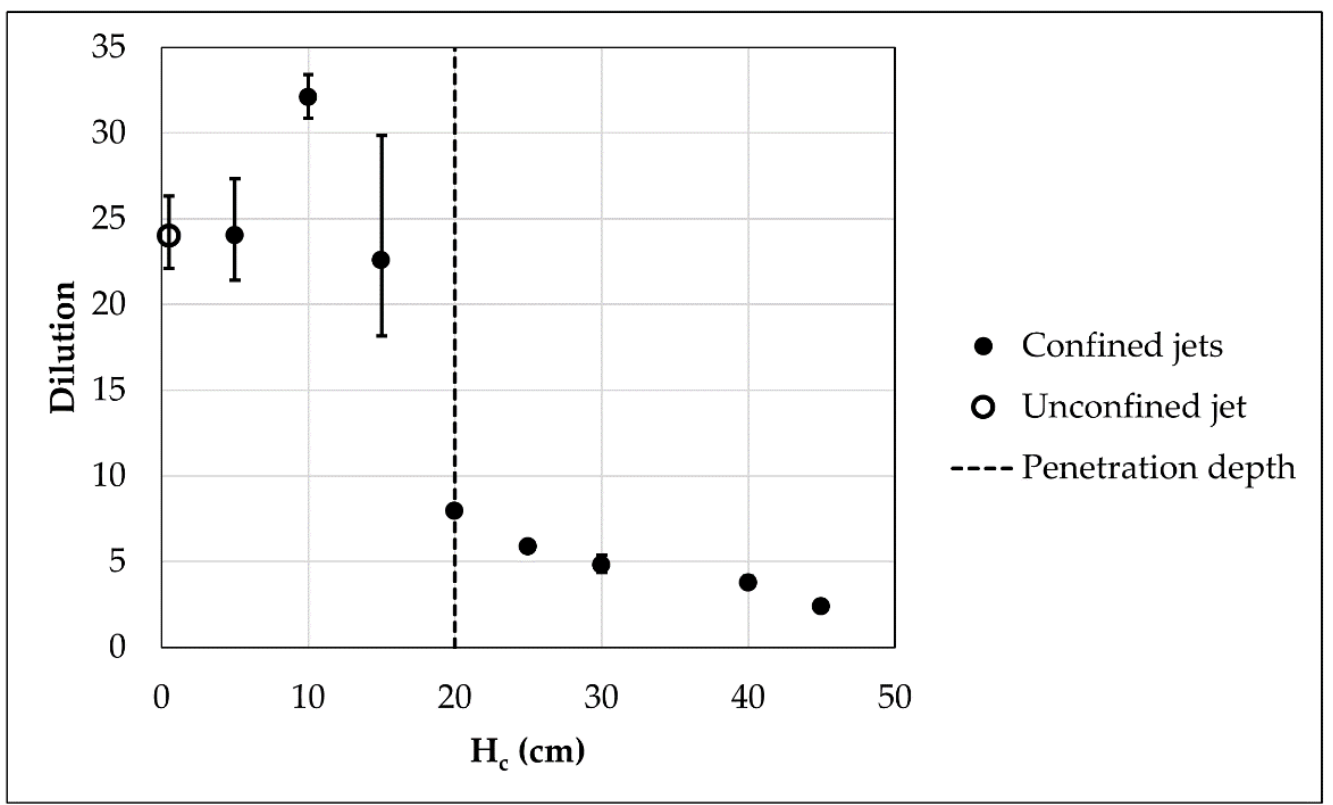

Figure 4. Dilution measurements for confined plunging jet experiments with $\mathrm{H}=50 \mathrm{~cm}, \mathrm{~L}_{\mathrm{j}}=60 \mathrm{~cm}$, $\mathrm{D}_{\mathrm{c}}=4.4 \mathrm{~cm}$ and $\Delta \mathrm{s}=10 \mathrm{psu}$. (Dilution of an unconfined plunging jet with $\mathrm{H}=50 \mathrm{~cm}, \mathrm{~L}_{\mathrm{j}}=60 \mathrm{~cm}$ and $\Delta \mathrm{s}=10 \mathrm{psu}$ is plotted at $\mathrm{H}_{\mathrm{c}} \approx 0$.)

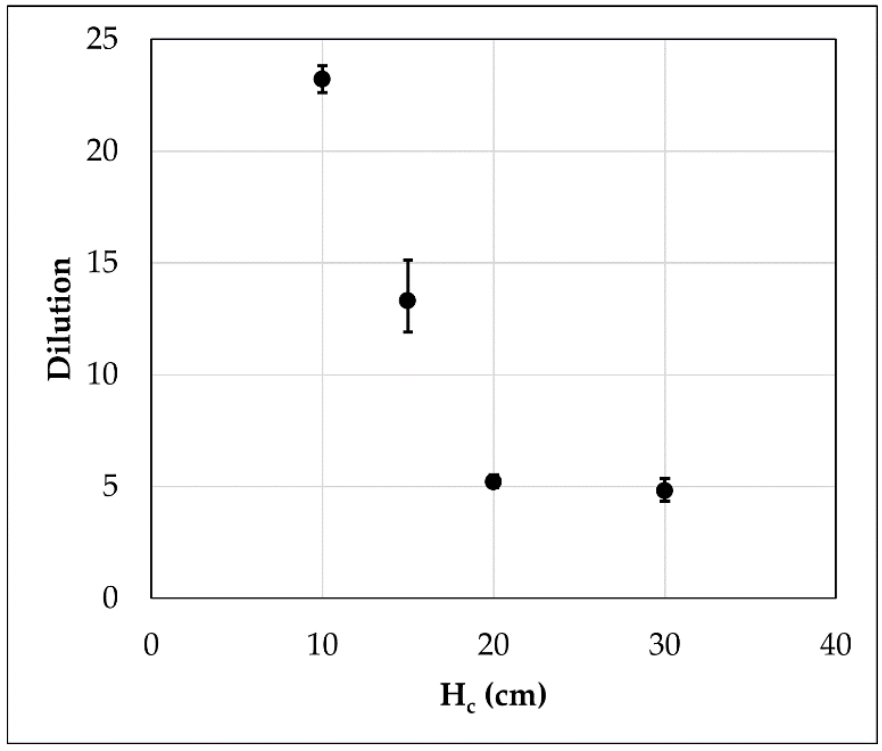

Figure 5. Dilution measurements for confined plunging jet experiments with $\mathrm{H}-\mathrm{H}_{\mathrm{c}}=20 \mathrm{~cm}$, $\mathrm{L}_{\mathrm{j}}=60 \mathrm{~cm}, \mathrm{D}_{\mathrm{c}}=4.4 \mathrm{~cm}$ and $\Delta \mathrm{s}=10 \mathrm{psu}$.

The bubble penetration depth for an unconfined jet with $\mathrm{L}_{\mathrm{j}}=60 \mathrm{~cm}$ and $\Delta \mathrm{s}=10 \mathrm{psu}$ was measured to be $20 \mathrm{~cm}$ and is also shown in Figure 4. A confined jet designed to increase aeration (by pushing the bubbles deeper than an unconfined jet) will have $\mathrm{H}_{c}$ greater than $20 \mathrm{~cm}$. The dilution of such confined plunging jets is less than the dilution of the unconfined jet. However, as shown in Figure 4, a confined jet can be designed to provide higher dilution than an unconfined jet by using a short downcomer $\left(\mathrm{H}_{\mathrm{c}}=10 \mathrm{~cm}\right)$. Experiments done with other jet lengths $\left(\mathrm{L}_{j}=15\right.$ and $\left.30 \mathrm{~cm}\right)$ also show higher dilution for a confined jet with $\mathrm{H}_{\mathrm{c}}=10 \mathrm{~cm}$ than that for an unconfined jet with the same jet length 
(Figure 6). The higher dilution for $\mathrm{H}_{\mathrm{c}}=10 \mathrm{~cm}$ as compared to the unconfined jet is likely because the presence of the downcomer reduces the momentum loss that the jet experiences upon impact with the water surface.

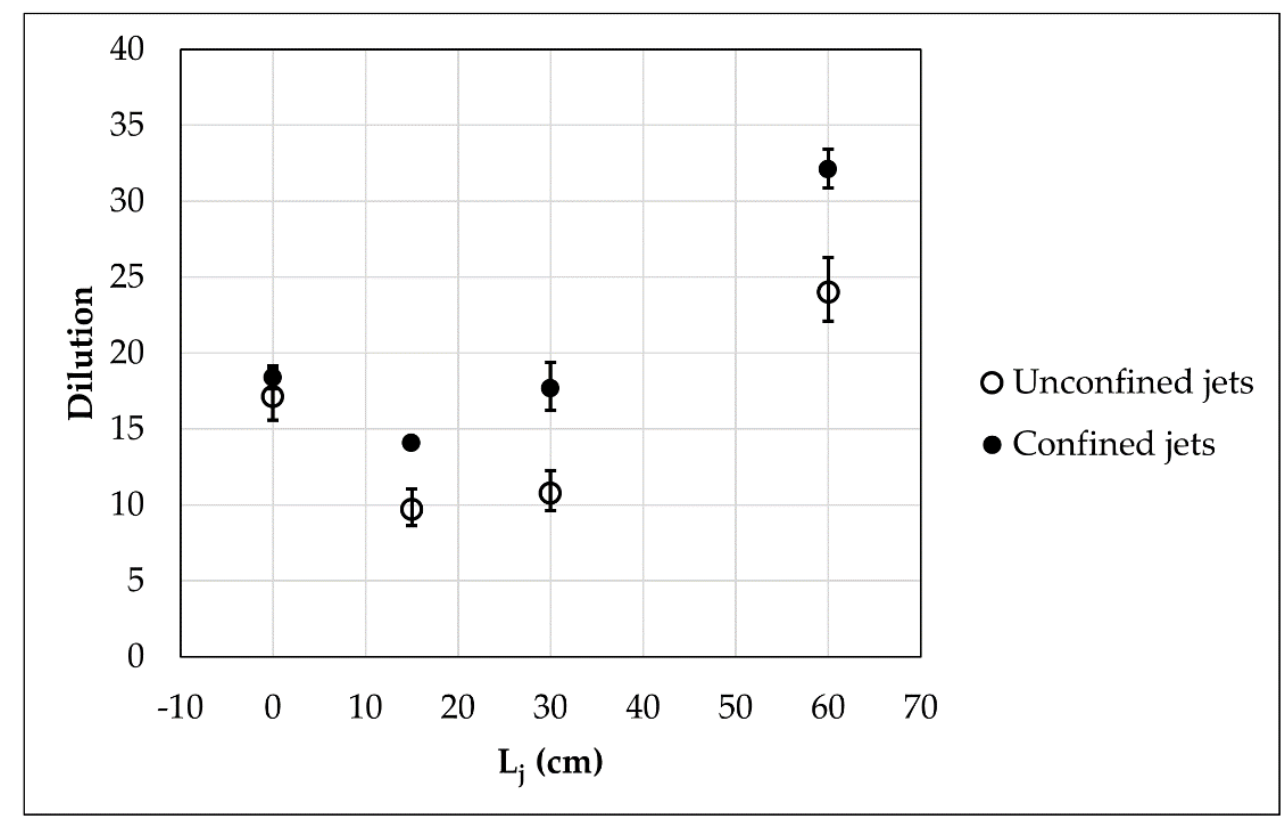

Figure 6. Comparison of dilution of confined jets with $\mathrm{H}_{\mathrm{c}}=10 \mathrm{~cm}$ and unconfined jets. $(\Delta \mathrm{s}=10 \mathrm{psu}$ for both unconfined and confined jets, $\mathrm{D}_{\mathrm{c}}=4.4 \mathrm{~cm}$ for the confined jets.).

In addition to these runs, some other experiments with other values of $D_{c}$ and $\Delta s$ also show that dilution decreases with increase in $\mathrm{H}_{\mathrm{c}}$ for long downcomers.

\subsubsection{Effect of Downcomer Diameter}

Experiments were conducted using downcomers with four different sizes to investigate the effect of downcomer diameter. For these experiments, the jet length was fixed at $60 \mathrm{~cm}$, and two values of $\mathrm{H}_{\mathrm{c}}(15$ and $30 \mathrm{~cm})$ and $\Delta \mathrm{s}(10$ and $40 \mathrm{psu})$ each were used. Figure 7 shows a plot of measured dilutions versus downcomer diameter. Dilution decreases with an increase in $D_{c}$ for narrow downcomers, but increases with an increase in $D_{c}$ for wide downcomers. This shift in dependence on $\mathrm{D}_{\mathrm{c}}$ occurs at $\mathrm{D}_{\mathrm{c}}$ between 5 and $10 \mathrm{~cm}\left(\right.$ or $\mathrm{D}_{\mathrm{c}} / \mathrm{d}_{0}$ between 5 and 10) depending on the value of $\mathrm{H}_{c}$.

For confined jets with long and narrow downcomers (for which most of the mixing takes place outside the downcomer), the flow of brine exiting from the bottom of the downcomer is uniform across its cross-section and the downward momentum of brine (M) decreases with increase in $D_{c}\left(M=\rho_{b} Q_{b} v\right.$, where $v=Q_{b} / A_{c}(1-n)$ is the downward velocity of brine inside the downcomer; $\mathrm{n}$ is the void ratio). Therefore, dilution also decreases with an increase in $D_{c}$.

For wide downcomers, the flow exiting from the bottom of the downcomer is not uniform (either radially or longitudinally). In fact, for some cases with large $D_{c}$ and $H_{c}$ (runs 2, 4, 6, and 8), no bubbles were seen escaping from the bottom of the downcomer suggesting non-uniform flow along the length of the downcomer (Figure 3). For confined jets with wide downcomers, dilution also takes place within the downcomer and the amount of ambient water available for entrainment within the downcomer increases with increase in $D_{c}$, resulting in an increase in dilution. This increase in dilution with $D_{c}$ is expected to continue for wider downcomers and asymptotically approach the dilution of an unconfined jet.

Chow et al. [10] made measurements of the width of the bubble plume for unconfined jets which can be used to estimate the size of a downcomer that would behave similarly to 
an unconfined jet. For unconfined jets with similar flow rate but smaller jet lengths (15 or $30 \mathrm{~cm}$ ) as the experiments done here, Chow et al. [10] measured the width of the bubble plume (W) to be between 14 and $20 \mathrm{~cm}$. A downcomer with $D_{c}>2 W$ (i.e., $D_{c}$ greater than about $30-40 \mathrm{~cm}$ ) should have enough "room" for entrainment and circulation of ambient water and should essentially behave as an unconfined jet.

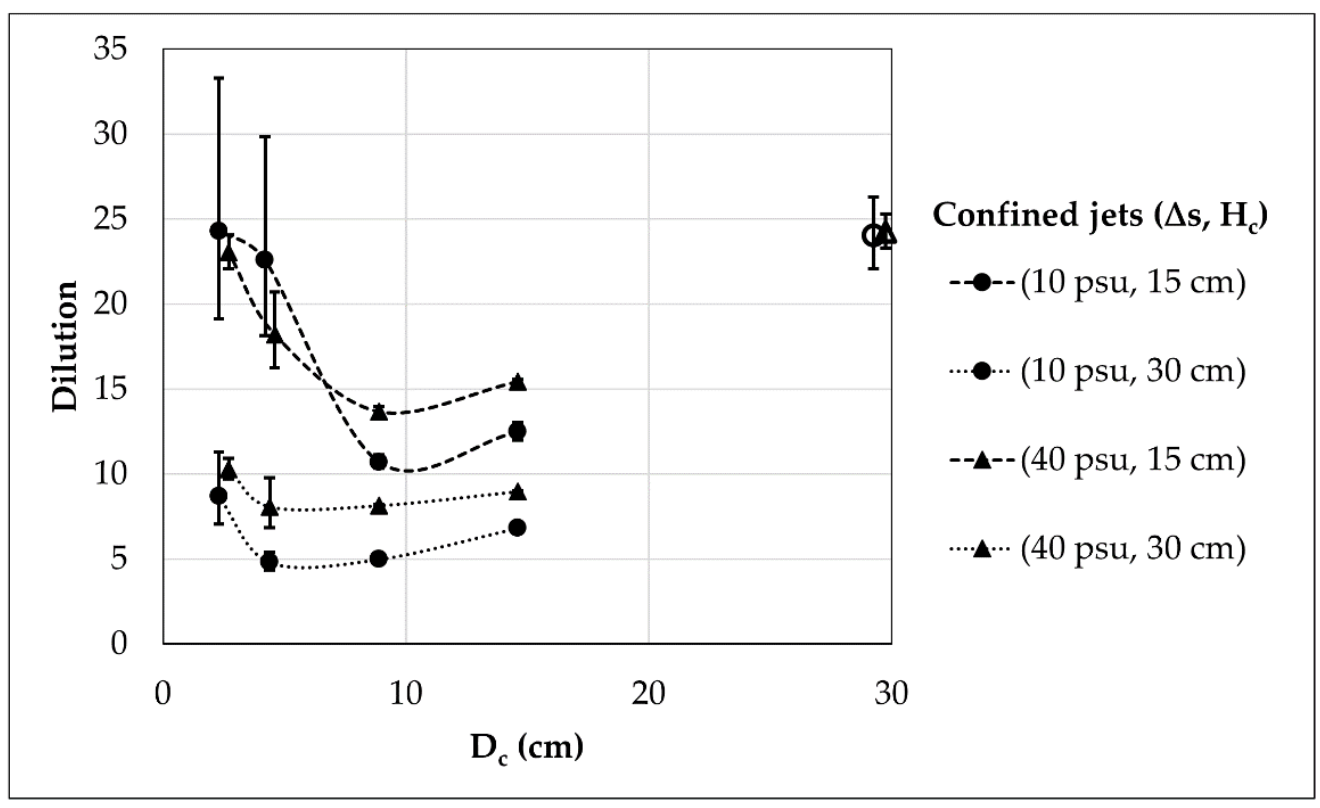

Figure 7. Plot of measured dilution as a function of downcomer diameter for experiments with $\mathrm{L}_{\mathrm{j}}=60 \mathrm{~cm}$. Dilution of unconfined jets is shown at large $\mathrm{D}_{\mathrm{c}}(\approx 30 \mathrm{~cm})$. (The abscissas of some runs are shifted slightly to avoid overlap.).

\subsubsection{Effect of Jet Length}

As previously shown in Figure 6, the effect of jet length on both unconfined and confined plunging jets is non-monotonic and is the same as observed by Chow et al. [10]. This trend is explained by considering the momentum of the jet. As the jet accelerates due to gravity when it is falling through the headspace, its momentum also increases. Therefore, a jet with a longer $L_{j}$ has higher momentum before it hits the water surface. However, the jet loses some of the momentum upon impact. The combination of these two effects leads to the non-monotonic trend with $\mathrm{L}_{\mathrm{j}}$. For $\mathrm{L}_{\mathrm{j}}=15 \mathrm{~cm}$, the loss in momentum is more than the increase due to gravity resulting in lower dilution than a jet with $\mathrm{L}_{j}=0$. However, as $\mathrm{L}_{j}$ increases further, the increase in momentum due to gravity is larger than the loss due to impact, and dilution increases with $\mathrm{L}_{\mathrm{j}}$.

Other than the runs shown in Figure 6, all the other runs have $L_{j}$ of 30 or $60 \mathrm{~cm}$. The dilution for runs with $\mathrm{L}_{j}=60 \mathrm{~cm}$ is higher than that of the corresponding runs with $\mathrm{L}_{\mathrm{j}}=30 \mathrm{~cm}$ because of the higher jet momentum.

\subsubsection{Effect of Brine Salinity}

The difference between dilution measurements for $\Delta \mathrm{s}=10$ and $40 \mathrm{psu}$ was small and a clear trend with brine salinity was not observed. While most experiments had higher dilution with $\Delta \mathrm{s}=40 \mathrm{psu}$, there are some cases for which the dilution was higher with $\Delta \mathrm{s}=10 \mathrm{psu}$ and some for which the measured dilutions were equal for the two salinities (Figure 7 and Table 1).

Several factors govern the effect of $\Delta s$ on dilution. First, the relative vertical position of the fluorescence probe with respect to the centerline of the bottom layer (i.e., the tank floor) is different for experiments with different $\Delta \mathrm{s}$ as the thickness of the bottom layer of diluted brine depends on the density (salinity) difference. The bottom layer is thinner for cases 
with higher density differences making the measurement location relatively farther from the centerline. Therefore, relatively lower concentration (compared to peak), i.e., higher dilution would be measured for $\Delta \mathrm{s}=40 \mathrm{psu}$. Second, in case of high dilution (absolute) for runs with $\Delta \mathrm{s}=10 \mathrm{psu}$, the density difference of diluted brine as compared to ambient water is small. In such cases, a well-defined bottom layer of diluted brine might not be formed; instead the diluted brine could be mixed over the water column resulting in high measured dilution. Third, the size of the bubbles decreases with increase in salinity [33]. Thus, it is possible that the movement of larger bubbles (for $\Delta s=10 \mathrm{psu}$ ) generates some additional mixing leading to higher dilution.

\section{Discussion}

As discussed in the previous section, all the variables of importance $\left(\mathrm{H}_{\mathrm{c}}, \mathrm{D}_{\mathrm{c}}, \mathrm{L}_{j}\right.$ and $\Delta \mathrm{s}$ ) affect dilution to differing extents, and in different ways, leading to complex, nonmonotonic trends. This point is highlighted in Figure 7, which shows effects of $D_{c}, H_{c}$ and $\Delta \mathrm{s}$ on dilution. Figure 7 shows a significant reduction in dilution as $\mathrm{H}_{\mathrm{c}}$ is increased from 15 to $30 \mathrm{~cm}$ for narrow downcomers. Change in downcomer diameter also leads to a significant change in dilution, especially when $D_{c}$ is increased from $2.5 \mathrm{~cm}$ to $8.9 \mathrm{~cm}$ with $\mathrm{H}_{\mathrm{c}}$ of $15 \mathrm{~cm}$. As compared to the effects of $\mathrm{H}_{\mathrm{c}}$ and $\mathrm{D}_{\mathrm{c}}$, the effect of $\Delta \mathrm{s}$ on dilution is small.

Results from the previous section can be used to discuss the effects of downcomer size $\left(\mathrm{H}_{\mathrm{c}}\right.$ and $\left.\mathrm{D}_{\mathrm{c}}\right)$ on bubble penetration depth and dilution. It is helpful to look at the effects of $\mathrm{H}_{\mathrm{c}}$ and $\mathrm{D}_{\mathrm{c}}$ by considering the four quadrants shown in Figure 8. For the experiments discussed here, the delineation between small and large $D_{c}$ is made at $D_{c} / d_{0}=6$. Short and long downcomers are delineated by comparing them to the bubble penetration depth of an unconfined jet $\left(\mathrm{H}_{\mathrm{pu}}\right)$, which is equal to $20 \mathrm{~cm}$.

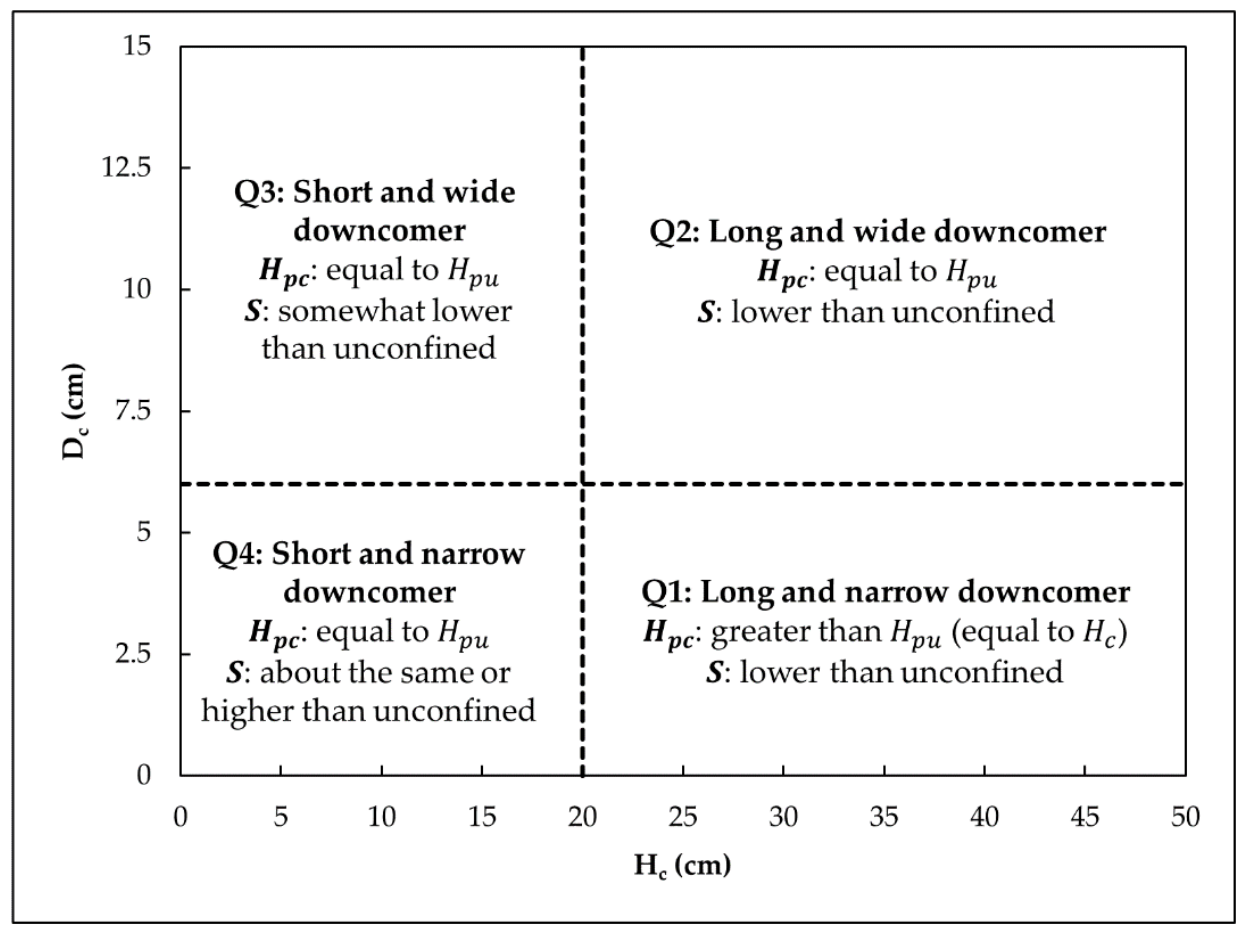

Figure 8. Bubble penetration depth $\left(\mathrm{H}_{\mathrm{pc}}\right)$ and dilution $(\mathrm{S})$ of confined plunging jets as functions of downcomer dimensions $\left(H_{c}\right.$ and $D_{c}$ ). (The delineation between small and large $D_{c}$ is made at $D_{c} / d_{0}$ $=6$. Short and long downcomers are delineated by comparing them to the bubble penetration depth of an unconfined jet $\left(\mathrm{H}_{\mathrm{pu}}\right)$ which is equal to $20 \mathrm{~cm}$.)

The penetration depth of bubbles is only increased by using long and narrow downcomers (Q1). Increase in bubble penetration depth would result in longer contact time when the bubbles are rising to the surface and hence potential increase in aeration depending 
on the rate of air entrainment. However, the presence of a long and narrow downcomer results in lower dilution as compared to an unconfined jet.

For confined jets with wide downcomers (Q2 and Q3), the reduction in dilution as compared to an unconfined jet is smaller, but the penetration depth is also not increased. Thus, a confined jet with a wide downcomer is not expected to provide better aeration than an unconfined jet.

Confined jets with short and narrow downcomers (Q4) generally provide the same dilution as unconfined jets. However, using a confined jet with a short downcomer can result in higher dilution than an unconfined jet $\left(\mathrm{H}_{\mathrm{c}}=10 \mathrm{~cm}\right.$ in the reported experiments). In this case, the bubble penetration depth was observed to be similar to an unconfined jet and both designs are expected to provide a comparable amount of aeration. Therefore, a design with a short downcomer might lead to an increase in dilution without a reduction in aeration. However, any benefit of this design with a downcomer will have to be weighed against a higher capital and operating (maintenance) cost.

In the above discussion, increase in bubble penetration depth is assumed to imply an increase in aeration because of the longer contact time between air and water. However, aeration also depends on the amount of net air entrained by the jet, which can be different for unconfined and confined plunging jets and also depends on the downcomer diameter and depth of submergence [22,26,29,30].

\section{Summary and Conclusions}

This paper evaluated confined plunging jets for disposal of reject brine from desalination plants. Previous studies had shown that confined plunging jets can be used to introduce air into the water column which can help reduce the possibility of low dissolved oxygen. However, it was not clear whether confined plunging jets can provide sufficient mixing of brine with ambient water to reduce its excess salinity. Therefore, experimental measurements of dilution of confined plunging jets discharging negatively buoyant effluent were presented in this paper. Dilution measurements showed non-monotonic dependence on important independent variables such as the jet length and the downcomer's diameter and submergence depth. However, dilution generally decreased with an increase in downcomer submergence depth. No significant effect of brine salinity on dilution was observed.

Observations of the bubble penetration depth were also made and showed that confined plunging jets can increase the depth of penetration of bubbles in comparison to unconfined jets if long, narrow downcomers are used. The penetration depth of bubbles was roughly the same as unconfined jets with wide downcomers of any depth.

The experiments done in this study showed a potential trade-off between dilution and aeration. The use of long and narrow downcomers can increase the penetration depth of bubbles and therefore increase the contact time between the gas and liquid phase, but it also results in a reduction of dilution. Only for some experiments with short downcomers, which showed an increase in dilution and no reduction in bubble penetration depth, was this trade-off not apparent. However, experimental measurements of the change in dissolved oxygen, i.e., aeration, need to be made to see if a confined plunging jet with a short downcomer can indeed provide the same aeration as an unconfined plunging jet. Measurements of the change in dissolved oxygen (aeration) also need to be made for confined jets with long and narrow downcomers to prove that such designs can indeed provide better aeration.

Author Contributions: Conceptualization, E.E.A. and B.A.-A.; Formal analysis, I.S. and E.E.A.; Funding acquisition, E.E.A., B.A.-A. and J.H.; Investigation, I.S.; Methodology, E.E.A. and B.A.-A.; Project administration, E.E.A., B.A.-A. and J.H.; Supervision, E.E.A. and J.H.; Validation, I.S. and A.C.C.; Visualization, I.S.; Writing—original draft, I.S.; Writing—review \& editing, I.S., E.E.A., B.A.-A., A.C.C. and J.H. All authors have read and agreed to the published version of the manuscript. 
Funding: This research was supported by Kuwait-MIT Center for Natural Resources and the Environment (CNRE), which was funded by Kuwait Foundation for the Advancement of Sciences (KFAS), project no. PN1815EV07.

Data Availability Statement: All data generated during the study appear in the article.

Conflicts of Interest: The authors declare no conflict of interest. The funders had no role in the design of the study; in the collection, analyses, or interpretation of data; in the writing of the manuscript, or in the decision to publish the results.

\section{Nomenclature}

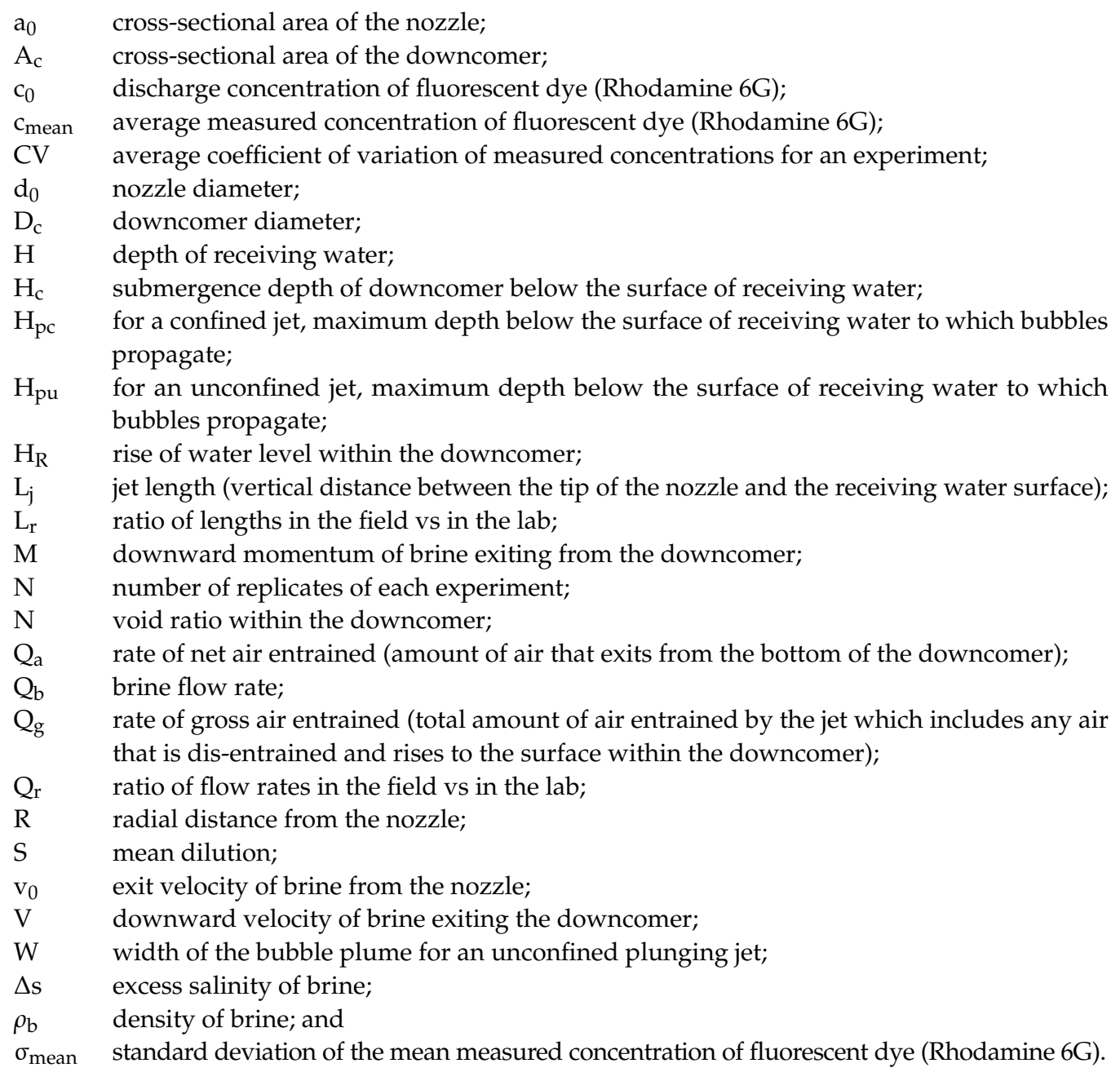

\section{References}

1. Lattemann, S.; Morelissen, R.; van Gils, J. Desalination capacity of the Arabian Gulf-Modeling, monitoring and managing discharges. In Proceedings of the International Desalination Association World Congress on Desalination and Water Reuse, Tianjin, China, 20-25 October 2013.

2. Bleninger, T.; Jirka, G.H. Environmental Planning, Prediction and Management of Brine Discharges from Desalination Plants; Middle East Desalination Research Center (MEDRC): Muscat, Oman, 2010.

3. Szeptycki, L.; Hartge, E.; Ajami, N.; Erickson, A.; Heady, W.N.; LaFeir, L.; Meister, B.; Verdone, L.; Kose, J.R. Marine and Coastal Impacts on Ocean Desalination in California. In A Report of Water in the West; Center for Ocean Solutions, Monterey Bay Aquarium and The Nature Conservancy: Monterey, CA, USA, 2016.

4. Missimer, T.M.; Maliva, R.G. Environmental issues in seawater reverse osmosis desalination: Intakes and outfalls. Desalination 2018, 434, 198-215. [CrossRef]

5. Jones, E.; Qadir, M.; van Vliet, M.T.H.; Smakhtin, V.; Kang, S. The state of desalination and brine production: A global outlook. Sci. Total Environ. 2019, 657, 1343-1356. [CrossRef] [PubMed] 
6. $\quad$ Roberts, P.J.W.; Jenkins, S.; Paduan, J.; Schlenk, D.; Weis, J. Management of Brine Discharges to Coastal Waters, Recommendations of a Science Advisory Panel; State Water Resources Control Board: Sacramento, CA, USA, 2012.

7. Jiang, B.; Law, A.W.K.; Lee, J.H.W. Mixing of $30^{\circ}$ and $45^{\circ}$ Inclined Dense Jets in Shallow Coastal Waters. J. Hydraul. Eng. 2014, 140, 241-253. [CrossRef]

8. Shrivastava, I.; Adams, E.E. Pre-dilution of desalination reject brine: Impact on outfall dilution in different water depths. J. Hydro Environ. Res. 2019, 24, 28-35. [CrossRef]

9. Shrivastava, I.; Adams, E.E. Effect of shallowness on dilution of unidirectional diffusers. J. Hydraul. Eng. 2019, 145, 06019013. [CrossRef]

10. Chow, A.C.; Shrivastava, I.; Adams, E.E.; Al-Rabaie, F.; Al-Anzi, B. Unconfined dense plunging jets used for brine disposal from desalination plants. Processes 2020, 8, 696. [CrossRef]

11. Hodges, B.R. The importance of mixing and isolation time for desalination brine discharge. In Proceedings of the International Engineering Conference on Hot Arid Regions (IECHAR 2010), Al-Ahsa, Saudi Arabia, 1-2 March 2010.

12. Hodges, B.R.; Furnans, J.E.; Kulis, P.S. Thin-Layer Gravity Current with Implications for Desalination Brine Disposal. J. Hydraul. Eng. 2011, 137, 356-371. [CrossRef]

13. Adams, E.E.; Shrivastava, I.; Chow, A.C. Vertical mixing of desalination reject brine that accumulates in local depressions after near field mixing. In Proceedings of the International Symposium on Outfall Systems (ISOS), Ottawa, ON, Canada, 10-13 May 2016.

14. Pietrafesa, L.J.; Miller, J.M. A Comparison of Fish Kills in the Pamlico and Neuse Rivers (a Symptom) and Implications for Estuarine Health; North Carolina State University: Raleigh, NC, USA, 1997.

15. Nestlerode, J.A.; Diaz, R.J. Effects of periodic environmental hypoxia on predation of a tethered Polychaete, Glycera americana: Implications for trophic dynamics. Mar. Ecol. Prog. Ser. 1998, 172, 185-195. [CrossRef]

16. Lin, J.; Lian, X.; Pietrafesa, L.J.; Shen, J.; Mallin, M.A.; Durako, M.J. Dissolved oxygen stratification in two micro-tidal partiallymixed estuaries. Estuar. Coast. Shelf Sci. 2006, 70, 423-437. [CrossRef]

17. USGS Dissolved Oxygen Solubility Tables. Available online: https://water.usgs.gov/water-resources/software/DOTABLES/ (accessed on 9 April 2021).

18. Stanley, D.W.; Nixon, S.W. Stratification and bottom-water hypoxia in the Pamlico River Estuary. Estuaries 1992, 15, $270-281$. [CrossRef]

19. Buzzelli, C.P.; Luettich, R.A., Jr.; Powers, S.P.; Peterson, C.H.; McNinch, J.E.; Pinckney, J.L.; Paerl, H.W. Estimating the spatial extent of bottomwater hypoxia and habitat degradation in a shallow estuary. Mar. Ecol. Prog. Ser. 2002, 230, 103-112. [CrossRef]

20. Breitburg, D.L.; Adamack, A.; Rose, K.A.; Kolesar, S.E.; Decker, M.B.; Purcell, J.E.; Keister, J.E.; Cowan, J.H., Jr. The pattern and influence of low dissolved oxygen in the Patuxent River, a seasonal hypoxic estuary. Estuaries 2003, 26, 280-297. [CrossRef]

21. Yamagiwa, K.; Oochira, Y.; Ohkawa, A. Performance evaluation of plunging liquid jet bioreactor with crossflow filtration for small-scale treatment of domestic wastewater. Bioresour. Technol. 1994, 58, 131-138. [CrossRef]

22. Bin, A.K. Gas entrainment by plunging liquid jets. Chem. Eng. Sci. 1993, 48, 3585-3630. [CrossRef]

23. Horan, N.J. Biological Wastewater Treatment System: Theory and Operation; John Wiley and Sons: Hoboken, NJ, USA, $1990 ;$ p. 60.

24. Low, K.C. Hydrodynamics and Mass Transfer Studies of a Confined Plunging Jet. Ph.D. Thesis, Department of Chemical Engineering, Loughborough University, Loughborough, UK, 2003.

25. Van de Donk, J.A.C. Water aeration with plunging jets. Ph.D. Thesis, Department of Applied Sciences, Delft University of Technology, Delft, The Netherlands, 1981.

26. Ohkawa, A.; Kusabiraki, D.; Kawai, Y.; Sakai, S.; Endoh, K. Some flow characteristics of a vertical liquid jet system having downcomers. Chem. Eng. Sci. 1986, 41, 2347-2361. [CrossRef]

27. Deswal, S.; Verma, D.V.S. Air-water oxygen transfer with multiple jets. Water Qual. Res. J. 2007, 42, 295-302. [CrossRef]

28. Ma, J.; Oberai, A.A.; Drew, D.A.; Lahey, R.T., Jr.; Moraga, F.J. A quantitative sub-grid entrainment model for bubbly flowsPlunging jets. Comput. Fluids 2010, 39, 77-86. [CrossRef]

29. Cumming, I.W.; Rielly, C.D.; Mason, A.J. Hydraulic performance of an annular plunging jet reactor. Chem. Eng. Res. Des. 2002, 80, 543-549. [CrossRef]

30. Al-Anzi, B.; Cumming, I.W.; Rielly, C.D. Air entrainment rates in a confined plunging jet reactor. In Proceedings of the 10th International Conference on Multiphase Flow in Industrial Plants, Tropea, Italy, 20-23 September 2006; pp. 71-82.

31. Al-Anzi, B. Effect of Primary Variables on A Confined Plunging Liquid Jet Reactor. Water 2020, 12, 764. [CrossRef]

32. Bayly, A.E.; Rielly, C.D.; Evans, G.M.; Hazell, M. The rate of expansion of a confined submerged jet. Proceedings of CHEMECA '92, Canberra, Australia, 1 January 1992; pp. 119-126.

33. Clift, R.; Grace, J.R.; Weber, M.E. Bubbles, Drops and Particles; Dover: Mineola, NY, USA, 1978. 